\title{
SPAG9 is overexpressed in osteosarcoma, and regulates cell proliferation and invasion through regulation of JunD
}

\author{
CHI XIAO ${ }^{1}$, LIN FU ${ }^{2}$, CHONGNAN YAN ${ }^{1}$, FENYONG SHOU ${ }^{1}$, QI LIU ${ }^{1}$, LEI LI $^{1}$, SHAOQIAN CUI ${ }^{1}$, \\ JINGZHU DUAN $^{1}$, GUOXIN JIN ${ }^{1}$, JIANHUA CHEN ${ }^{1}$, YUANMING BIAN ${ }^{1}$, XU WANG $^{1}$ and HUAN WANG ${ }^{1}$ \\ ${ }^{1}$ Department of Orthopaedics, Shengjing Hospital of China Medical University, Shenyang, Liaoning 110004; \\ ${ }^{2}$ Department of Pathology, China Medical University, Shenyang, Liaoning 110001, P.R. China
}

Received March 15, 2015; Accepted April 4, 2016

DOI: $10.3892 / 01.2016 .4920$

\begin{abstract}
Sperm-associated antigen 9 (SPAG9) is a recently characterized oncoprotein that is considered to be involved in several forms of malignant tumor. However, its biological function and expression pattern in human osteosarcoma have not yet been elucidated. In the present study, SPAG9 expression was analyzed in 58 cases of human osteosarcoma by immunohistochemistry. The results demonstrated that SPAG9 was overexpressed in $63.8 \%$ (37/58) of osteosarcoma tissues, while normal bone tissues exhibited negative SPAG9 expression. SPAG9 small interfering RNA was employed in the U2OS cell line, which has high endogenous expression, and SPAG9 transfection was performed in the MG63 cell line, which has low endogenous expression. MTT and Matrigel invasion assays demonstrated that SPAG-9-knockdown significantly reduced U2OS cell invasion and proliferation, while SPAG9 transfection enhanced MG63 cell proliferation and invasion. Furthermore, it was observed that SPAG9 positively regulated cyclin D1, phosphorylated-c-Jun NH2-terminal kinase (JNK) and JunD expression. Treatment with the JNK inhibitor, SP600125, abolished the upregulatory effect of SPAG9 on JunD. Taken together, the present study identified SPAG9 as a critical oncoprotein involved in osteosarcoma proliferation and invasion, possibly functioning through JNK-JunD signaling.
\end{abstract}

\section{Introduction}

Osteosarcoma is a common adolescent cancer, which comprises $\sim 20 \%$ of all forms of primary bone cancer (1). The survival rate for osteosarcoma has remained relatively poor for the last 30 years and is $\sim 60 \%$ worldwide $(2,3)$. The identification of novel oncogenic targets and the underlying molecular events that promote the malignant growth, invasion and metastasis

Correspondence to: Professor Huan Wang, Department of Orthopaedics, Shengjing Hospital of China Medical University, 36 Sanhao Street, Heping, Shenyang, Liaoning 110004, P.R. China E-mail: wanghuancmu@163.com

Key words: SPAG9, osteosarcoma, proliferation, invasion, JunD of osteosarcoma may aid the development of successful treatment strategies for patients with the disease (4-6).

Cancer/testis (CT) antigens are proteins that are typically expressed in the human germ line. A number of studies have demonstrated that these proteins are upregulated in various forms of cancer, and may therefore be targeted by therapeutic cancer vaccines (7).

Sperm-associated antigen 9 (SPAG9) was originally identified as a novel member of the CT antigen family, and functions as a scaffolding protein involved in the activation of the c-Jun NH2-terminal kinase (JNK) signaling pathway (8-12). Previous studies have reported that SPAG9 is overexpressed in various types of human cancer, including breast, thyroid and cervical cancer, and colorectal carcinoma (13-17). SPAG9 small interfering RNA (siRNA) treatment in cancer cells was reported to inhibit tumor cell growth and invasion. In addition, SPAG9 protein expression in tumors was observed to be associated with circulating SPAG9 antibodies in the serum of patients with early-stage breast and cervical cancer $(13,14)$, indicating its potential application in early cancer detection. To date, the expression pattern and biological function of SPAG9 in human osteosarcoma remains unknown.

In the present study, the expression pattern of SPAG9 in 58 osteosarcoma specimens was investigated. In addition, the potential effects of SPAG9 on cell proliferation and invasion were examined in U2OS and MG63 osteosarcoma cell lines.

\section{Materials and methods}

Patients and specimens. The study protocol was approved by the Institutional Review Board of Shengjing Hospital of China Medical University (Shenyang, China). Primary tumor specimens were obtained from 58 patients diagnosed with osteosarcoma who underwent resection at the First Affiliated Hospital of China Medical University (Shenyang, China) and Shengjing Hospital of China Medical University between March 2000 and May 2014. Normal bone specimens were obtained from normal tissues adjacent to the osteosarcoma tissues. Tissues were formalin-fixed and embedded in paraffin prior to use. Tissue sections were stained with hematoxylin and eosin, and the histological diagnosis was performed according to the World Health Organization classification 
guidelines (18). Clinical and histopathological data were obtained from medical records. According to the Enneking scoring system, the tumors were classified as highly malignant intracompartmental osteogenic sarcomas (IIA) or as extracompartmental lesions (IIB).

Cell culture and transfection. U2OS and MG63 cell lines were obtained from the American Type Culture Collection (Manassas, VA, USA). The cells were cultured for 2 days at $37^{\circ} \mathrm{C}$ in minimum essential medium (Invitrogen; Thermo Fisher Scientific, Inc., Waltham, MA, USA) containing 10\% fetal calf serum, $100 \mathrm{IU} / \mathrm{ml}$ penicillin and $100 \mu \mathrm{g} / \mathrm{ml}$ streptomycin (Sigma-Aldrich, St. Louis, MO, USA).

Smartpool siRNA targeting SPAG9 was purchased from Dharmacon (GE Healthcare Dharmacon Inc., Lafayette, CO, USA). DharmaFECT 2 Transfection Reagent (GE Healthcare Dharmacon Inc.) was used for siRNA transfection according to the manufacturer's protocol. Protein level was assessed $48 \mathrm{~h}$ later by western blotting.

Immunohistochemistry. Paraffin-embedded osteosarcoma tissues were cut into $4-\mu \mathrm{m}$ thick sections prior to immunostaining. Immunostaining was performed using the EliVision ${ }^{\mathrm{TM}}$ Plus Immunohistochemical Detection kit (Fuzhou Maixin Biotech Co., Ltd., Fuzhou, China). The sections were deparaffinized in xylene, rehydrated with graded alcohol and subsequently boiled in citrate buffer ( $\mathrm{pH}$ 6.0) for $2 \mathrm{~min}$ with an autoclave. Endogenous peroxidase was blocked by $3 \%$ hydrogen peroxide, and normal animal serum (Pierce Biotechnology, Inc., Rockford, IL, USA) was used to reduce non-specific binding. Tissue sections were incubated with polyclonal rabbit anti-SPAG9 antibody (dilution, 1:300; \#ab12331; Abcam, Cambridge, MA, USA) overnight at $4^{\circ} \mathrm{C}$. Rabbit immunoglobulin (dilution, 1:300; \#ab150062; Abcam) was used (at the same concentration as the antigen-specific antibody) as a negative control. Primary staining was followed by incubation with biotinylated anti-horseradish peroxidase secondary antibodies (dilution, 1:2,000; \#ab34885; Abcam). The peroxidase reaction was developed with 3,3'-diaminobenzidine (Fuzhou Maixin Biotech Co., Ltd.). Counterstaining with hematoxylin was performed and the sections were dehydrated in ethanol prior to mounting.

Immunostaining of SPAG9 was scored on a semiquantitative scale by evaluating the percentage and intensity of tumor cells according to a previous study (19). A total of 400 tumor cells were counted by microscope and the percentage of positively-stained cells was calculated. The intensity of SPAG9 staining was scored as follows: 0 , negative/weak; 1 , moderate; and 2, strong. Percentage scores were assigned as follows: $1,1-25 \% ; 2,26-50 \% ; 3,51-75 \%$; and 4, 76-100\%. The scores of each tumor sample were multiplied to give a final score between $0-8$, and a tumor sample score of $\geq 4$ was considered to indicate overexpression.

Quantitative polymerase chain reaction ( $q P C R$ ). Template DNA was obtained from U2OS and MG63 cells. qPCR was performed using the SYBR ${ }^{\circledR}$ Green PCR Master Mix (Applied Biosystems; Thermo Fisher Scientific, Inc.) in a total volume of $20 \mu \mathrm{l}$ on a 7500 Real-Time PCR system (Applied Biosystems; Thermo Fisher Scientific, Inc.). The cycling conditions were as follows: $95^{\circ} \mathrm{C}$ for $30 \mathrm{sec} ; 40$ cycles of $95^{\circ} \mathrm{C}$ for $30 \mathrm{sec}$ and $60^{\circ} \mathrm{C}$ for $30 \mathrm{sec}$. A dissociation step was performed to generate melting curves to confirm the specificity of the amplification. PCR was repeated three times. Expression levels of the analyzed genes were normalized to the expression of $\beta$-actin. The fold change of gene expression was calculated by the $2^{-\Delta \Delta \mathrm{Cq}}$ method (20). The sequences of the primer pairs were as follows: SPAG9 forward, 5'-GCTTTTGATCGCAATACA GAATCTC-3'; and reverse, 5'-AACTTCCCGACCCATTCC TAGT-3'; and $\beta$-actin forward, 5'-ATAGCACAGCCTGGA TAGCAACGTAC-3' and reverse, 5'-CACCTTCTACAATGA GCTGCGTGTG-3'. The primers were designed by Oligo 7 software (www.oligo.net).

Western blot analysis. Total protein was extracted from cells using cell lysis buffer (Pierce Biotechnology, Inc.) and quantified using the Bradford method. Samples were separated by $10 \%$ sodium dodecyl sulfate polyacrylamide gel electrophoresis and were transferred to polyvinylidene fluoride membranes (EMD Millipore, Billerica, MA, USA) where they were incubated overnight at $4^{\circ} \mathrm{C}$ with antibodies against SPAG9 (dilution, 1:1,000; \#ab12331; Abcam), cyclin D1 (dilution, 1:1,000; \#2978; Cell Signaling Technology, Inc., Danvers, MA , USA), phosphorylated (p)-JNK (dilution, 1:1,000; \#4668; Cell Signaling Technology, Inc.), JNK (dilution, 1:1,000; \#9252; Cell Signaling Technology, Inc.), JunD (dilution, 1:1,000; \#5000; Cell Signaling Technology, Inc.) and glyceraldehyde 3-phosphate dehydrogenase (dilution, 1:1,000; \#2118; Cell Signaling Technology, Inc.). Following incubation with peroxidase-coupled anti-mouse/rabbit immunoglobulin $\mathrm{G}$ (Cell Signaling Technology, Inc.) at $37^{\circ} \mathrm{C}$ for $2 \mathrm{~h}$, bound proteins were visualized using ECL Western Blotting Substrate (Pierce Biotechnology, Inc.) and detected using a BioImaging system (UVP Inc., Upland, CA, USA). Relative protein levels were quantified using $\beta$-actin as a loading control and ImageJ $1.48 \mathrm{v}$ software (National Institutes of Health, Bethesda, MD, USA).

Transwell invasion and MTT assays. Cell invasion was performed in a 24 -well Transwell chamber $(8-\mu \mathrm{m}$ pore size; Costar, Corning, NY, USA). The insert was coated with $50 \mathrm{ml}$ Matrigel (dilution, 1:3; BD Bioscience, Franklin Lakes, NJ, USA). U2OS cells were trypsinized following transfection with negative control or SPAG9 siRNA for $48 \mathrm{~h}$ at $37^{\circ} \mathrm{C}$, and were subsequently transferred to the upper chamber in $100 \mathrm{ml}$ serum-free medium containing $1 \times 10^{5}$ cells and incubated for $24 \mathrm{~h}$. The lower chamber was filled with medium supplemented with $10 \%$ fetal bovine serum (Pierce Biotechnology, Inc.) as chemoattractant. The membranes were fixed and stained using $0.1 \%$ crystal violet. The number of invading cells were counted in five randomly selected high-power fields (magnification, $\mathrm{x} 400$ ) under a microscope. All experiments were performed in triplicate.

For the MTT assay, the cells were plated in 96-well plates at a concentration of $\sim 2,000$ cells per well and cultured for 3 days. For quantification of cell viability, $20 \mu 15 \mathrm{mg} / \mathrm{ml}$ MTT (thiazolyl blue) solution was added to each well and incubated for $4 \mathrm{~h}$ at $37^{\circ} \mathrm{C}$. The medium was removed from each well and the resulting MTT formazan was solubilized in $200 \mu \mathrm{l}$ dimethyl sulfoxide. The solution was measured spectrophotometrically at $490 \mathrm{~nm}$. 
Table I. Association between SPAG9 and clinicopathological features.

\begin{tabular}{lcccc}
\hline \multirow{2}{*}{$\begin{array}{l}\text { Clinical } \\
\text { parameters }\end{array}$} & $\mathrm{n}$ & \multicolumn{2}{c}{ SPAG9 } & \\
& & Negative & Positive & P-value \\
\hline Age, years & & & & \\
$\quad<18$ & 28 & 10 & 18 & 0.9399 \\
$\geq 18$ & 30 & 11 & 19 & \\
Gender & & & & \\
$\quad$ Male & 36 & 12 & 24 & 0.5602 \\
Female & 22 & 9 & 13 & \\
$\begin{array}{l}\text { Pathological } \\
\text { classification }\end{array}$ & & & & \\
$\quad$ IIA & 10 & 4 & 6 & 0.7838 \\
IIB & 48 & 17 & 31 & \\
Location & & & & \\
$\quad$ Extremities & 47 & 16 & 31 & 0.4784 \\
Axial & 11 & 5 & 6 & \\
\hline
\end{tabular}

SPAG9, sperm-associated antigen 9.
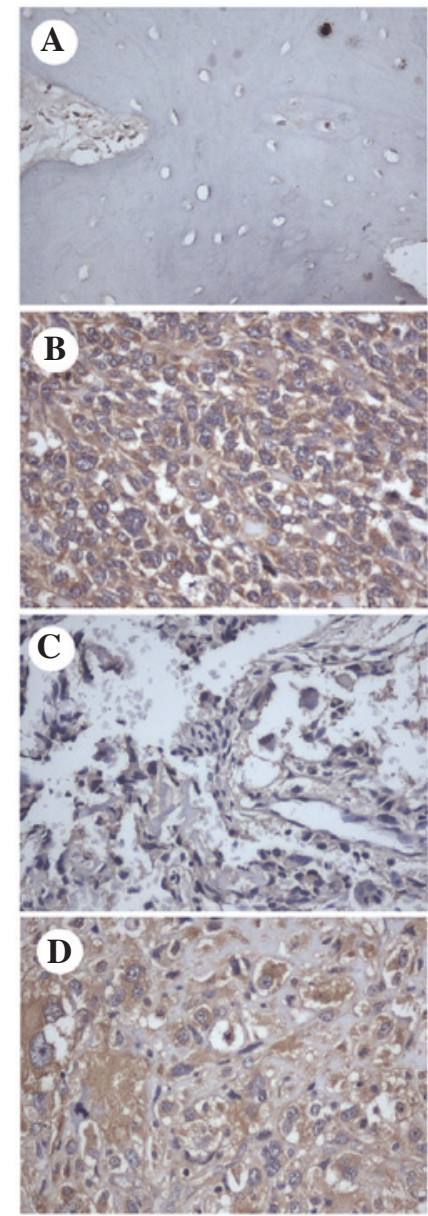

Figure 1. Expression of SPAG9 protein in osteosarcoma tissues. (A) Negative SPAG9 expression in normal bone tissue. (B) Positive cytoplasmic SPAG9 expression in a case of stage IIA osteosarcoma. (C) Negative staining of SPAG9 in a case of stage IIB osteosarcoma. (D) Positive cytoplasmic SPAG9 expression in a case of stage IIB osteosarcoma. Magnification, x400. SPAG, sperm-associated antigen 9.
A
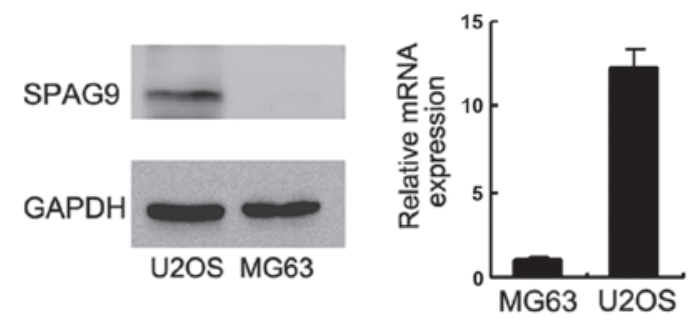

B
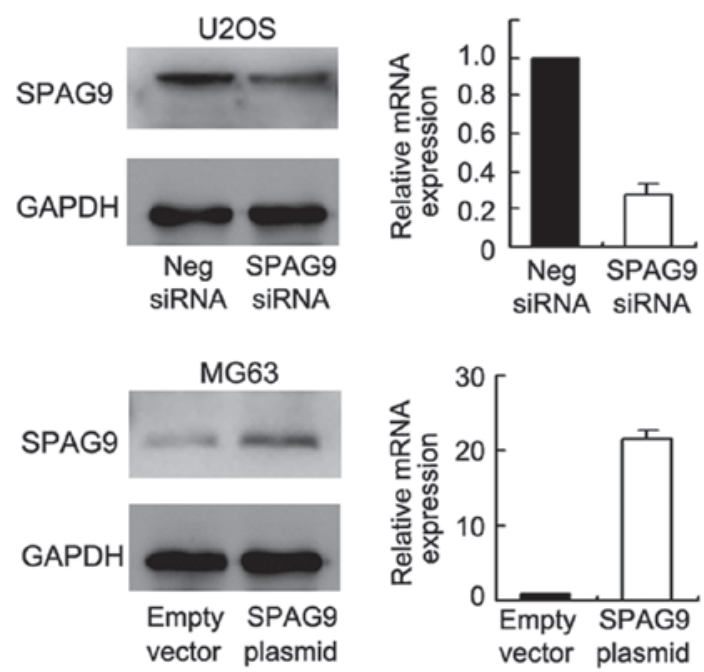

Figure 2. SPAG-knockdown and transfection efficiency in osteosarcoma cell lines. (A) Quantitative polymerase chain reaction analysis and western blotting demonstrated high SPAG9 expression in the U2OS cell line and weak expression in the MG63 cell line. (B) siRNA knockdown markedly decreased SPAG9 levels in the U2OS cells in comparison with cells transfected with negative siRNA. Transfection of SPAG9 increased the protein and mRNA levels of SPAG9 in the MG63 cell line. SPAG3; sperm-associated antigen 9; siRNA, small interfering RNA; GAPDH, glyceraldehyde 3-phosphate dehydrogenase.

Statistical analysis. SPSS version 11.5 (SPSS, Inc., Chicago, IL, USA) was used for all statistical analyses. The $\chi^{2}$ test was used to examine associations between SPAG9 expression and clinicopathological factors, whilst Student's t-test was used to compare invasive cells and colony numbers between control and SPAG9 depletion cells. All P-values are based on two-sided statistical analysis, and $\mathrm{P}<0.05$ was considered to indicate a statistically significant difference.

\section{Results}

Expression pattern of SPAG9 in osteosarcoma tissues. In the normal bone tissues, SPAG9 staining was negative (Fig. 1A). By contrast, SPAG9 overexpression was observed in 37 out of 58 (63.8\%) human osteosarcoma tissues (Fig. 1B-D), while no staining was observed in sections from the same specimens incubated with non-immune rabbit immunoglobulin. SPAG9 was primarily localized in the cytoplasm of the osteosarcoma cells. The association between SPAG9 protein expression and clinicopathological factors was analyzed, and no association was identified between SPAG9 expression and age, gender, pathological classification or location (Table I).

Biological functions of SPAG9 in osteosarcoma cells. To determine the biological functions of SPAG9 in osteosarcoma 
$\mathbf{A}$
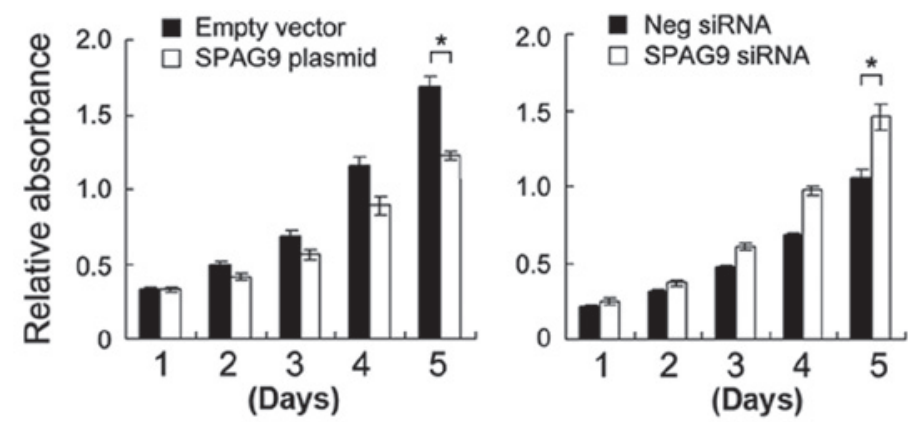

B
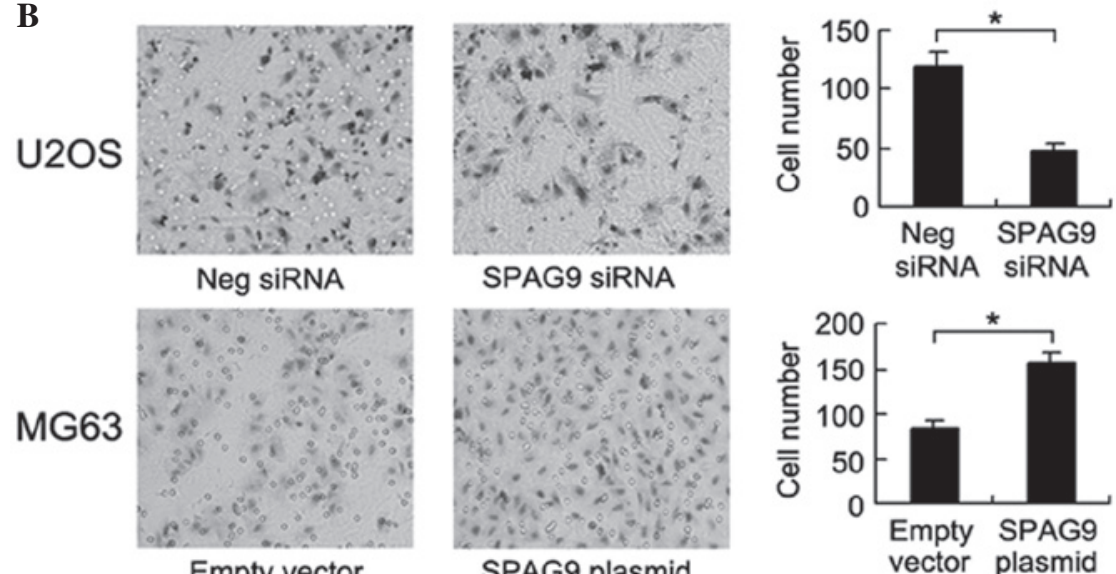

SPAG9 SIRNA
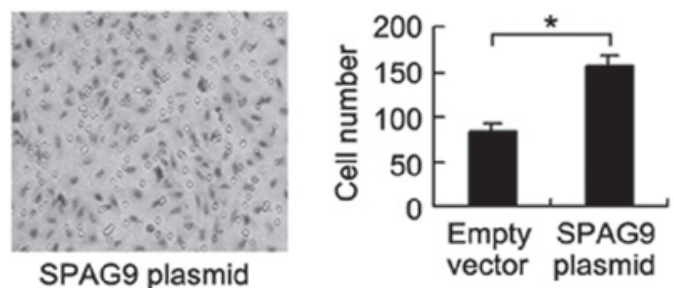

Figure 3. SPAG9 regulates proliferation and invasion of osteosarcoma cell lines. (A) MTT assay demonstrated that SPAG9 depletion in the U2OS cells inhibited cell proliferation, and SPAG9 transfection in the MG63 cells facilitated cell proliferation. (B) Transwell assay demonstrated that SPAG9 depletion inhibited cell invasion in the U2OS cell lines, and SPAG9 transfection in the MG63 cells facilitated cell invasion. "P<0.05. SPAG3; sperm-associated antigen 9; siRNA, small interfering RNA.

A

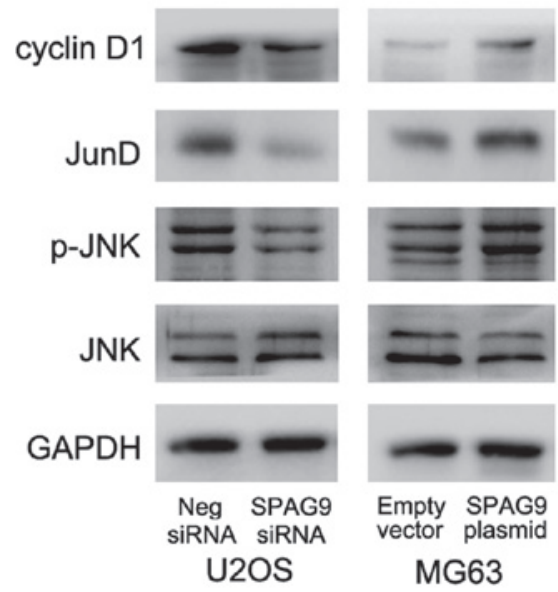

B

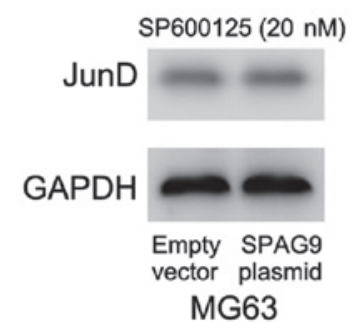

Figure 4. SPAG9 regulates proliferation and invasion through JunD and JNK. (A) SPAG9 depletion in the U2OS cells decreased while SPAG9 transfection increased cyclin D1, JunD and phosphorylated-JNK expression in the MG63 cells. (B) SP600125 treatment abolished the upregulatory effect of SPAG9 on JunD in the MG63 cell line. SPAG3; sperm-associated antigen 9; siRNA, small interfering RNA; JNK, c-Jun NH2-terminal kinase; GAPDH, glyceraldehyde 3-phosphate dehydrogenase. cell lines, the present study initially examined SPAG9 protein expression in the U2OS and MG63 cell lines. It was observed that SPAG9 expression was potent in the U2OS cells and weak in the MG63 cells (Fig. 2A). To examine the effect of SPAG9 on cell proliferation and invasion, siRNA-mediated SPAG9-knockdown was performed in the U2OS cell line and plasmid transfection was performed in the MG63 cell line. As presented in Fig. 2B, SPAG9 siRNA decreased SPAG9 protein and mRNA expression in the U2OS cells, and plasmid transfection upregulated SPAG9 expression in the MG63 cells. The MTT assay was employed to examine the role of SPAG9 on cell proliferation. The results demonstrated that SPAG9 siRNA inhibited the cell growth rate in the U2OS cells, and SPAG9 transfection upregulated cell proliferation in the MG63 cells (Fig. 3A). A Transwell assay was employed to characterize the effect of SPAG9 on cell invasion. As presented in Fig. 3B, SPAG9 depletion significantly inhibited cell invasion in the U2OS cell line (control vs. siRNA, $119 \pm 12$ vs. $48 \pm 6$; $\mathrm{P}<0.05$ ) and its transfection accelerated cell invasion in the MG63 cell line (empty vector vs. plasmid, $83 \pm 9$ vs. $156 \pm 12 ; \mathrm{P}<0.05$ ).

SPAG9 regulates JunD expression in osteosarcoma cells. Consistent with a previous study (19), the results of the present study indicated that SPAG9 is a regulator of osteosarcoma cell proliferation and invasion. It has previously been reported that SPAG9 is involved in JNK signaling (21). To investigate the mechanisms underlying this association, the current study examined the protein level of JunD following SPAG9-knockdown and transfection. As presented in Fig. 4A, 
SPAG9 depletion decreased cyclin D1 and JunD expression, and JNK phosphorylation in the U2OS cell line. In the MG63 cells, SPAG9 transfection increased JNK phosphorylation, and cyclin D1 and JunD protein expression (Fig. 4A). Treatment with the JNK inhibitor, SP600125 (20 nM, 3 h post-transfection), abolished the upregulatory effect of SPAG9 on JunD (Fig. 4B), indicating that SPAG9 may regulate the malignant biological behavior of osteosarcoma cells through JNK-JunD regulation.

\section{Discussion}

In the present study, it was observed that the level of SPAG9 expression was elevated in osteosarcoma tissues compared with that in normal bone specimens. In vitro experiments in osteosarcoma cell lines demonstrated that SPAG9 depletion inhibited proliferation and invasion, while SPAG9 transfection accelerated proliferation and invasion. In addition, it was observed that SPAG9 was able to regulate JunD expression.

SPAG9 has previously been identified to be overexpressed in various types of cancer, including lung, breast, renal, hepatocellular and colorectal cancer $(13,17,19,21,22)$. The current study observed negative SPAG9 staining in normal bone tissues, and positive cytoplasmic SPAG9 expression in $63.8 \%$ (37/58) of osteosarcoma tissues, which was consistent with previous studies (19,. A number of studies have described the role of SPAG9 in cancer cell proliferation and provided accumulating evidence that characterizes SPAG9 as an oncoprotein regulating cell invasion. It was reported that SPAG9 siRNA knockdown inhibited cell invasion and proliferation in renal, lung and colorectal carcinoma $(13,21,23-25)$. To gain insight into the function of SPAG9 in osteosarcoma progression, SPAG9 expression was knocked down in the U2OS cell line and upregulated in the MG63 cell line in the present study. Consistent with a former study $(19,26,27)$, it was demonstrated that SPAG9 depletion significantly inhibited cell proliferation and invasion, whilst SPAG9 plasmid transfection upregulated proliferation and invasion. These results suggested that SPAG9 serves an important role in osteosarcoma progression and may function as a biomarker for malignant behavior.

In the current study, the molecular pathway through which SPAG9 promotes osteosarcoma invasion and proliferation was also investigated. It was observed that SPAG9 was involved in JNK signaling; thus, JNK activation and its downstream target JunD, which serves as a link between JNK and cancer progression, was examined. Using western blot analysis, it was demonstrated that SPAG9 siRNA treatment downregulated p-JNK and JunD protein expression, whilst SPAG9 plasmid transfection upregulated the level of p-JNK and JunD. JunD is a component of the activator protein-1 transcription factor complex, which is important in cancer progression (28). A previous study reported that JunD activated cell proliferation via upregulation of cyclin D1 proteins (29), and was also demonstrated to activate matrix metalloproteinase (MMP)-7 and MMP-9 transcription (30,31). MMP-7 and MMP-9 have been suggested to be critical for the metastatic and invasive potential in human malignancies, including osteosarcoma (32-35). Thus, when combined, these results suggest that SPAG9 may induce osteosarcoma cell proliferation and invasion through JNK-JunD signaling. Furthermore, a previous study reported that inhibition of JNK signaling facilitates flavonoid-induced apoptosis in osteosarcoma cells via downregulation of JunD, indicating that JunD functions as an oncoprotein during osteosarcoma progression (36).

In conclusion, the present study established that SPAG9 is overexpressed in human osteosarcoma tissues. The results demonstrated that SPAG9 facilitated osteosarcoma cell proliferation and invasion, possibly through regulation of JNK-JunD signaling. Based on these findings, it may be concluded that SPAG9 is an important oncogene and may function as a potential therapeutic target in human osteosarcoma.

\section{Acknowledgements}

The present study was supported by the National Natural Science Foundation of China (grant no. 81271995).

\section{References}

1. Ottaviani G and Jaffe N: The epidemiology of osteosarcoma. Cancer Treat Res 152: 3-13, 2009.

2. Heare T, Hensley MA and Dell'Orfano S: Bone tumors: Osteosarcoma and Ewing's sarcoma. Curr Opin Pediatr 21: 365-372, 2009.

3. Levings PP, McGarry SV, Currie TP, Nickerson DM, McClellan S, Ghivizzani SC, Steindler DA and Gibbs CP: Expression of an exogenous human Oct-4 promoter identifies tumor-initiating cells in osteosarcoma. Cancer Res 69: 5648-5655, 2009.

4. Fujiwara M, Kashima TG, Kunita A, Kii I, Komura D, Grigoriadis AE, Kudo A, Aburatani $\mathrm{H}$ and Fukayama M: Stable knockdown of S100A4 suppresses cell migration and metastasis of osteosarcoma. Tumour Biol 32: 611-622, 2011.

5. Hua Y, Jia X, Sun M, Zheng L, Yin L, Zhang L and Cai Z: Plasma membrane proteomic analysis of human osteosarcoma and osteoblastic cells: Revealing NDRG1 as a marker for osteosarcoma. Tumour Biol 32: 1013-1021, 2011

6. Sharili AS, Allen S, Smith K, Hargreaves J, Price J and McGonnell I: Expression of Snail2 in long bone osteosarcomas correlates with tumour malignancy. Tumour Biol 32: 515-526, 2011.

7. Simpson AJ, Caballero OL, Jungbluth A, Chen YT and Old LJ: Cancer/testis antigens, gametogenesis and cancer. Nat Rev Cancer 5: 615-625, 2005.

8. Ando K, Uemura K, Kuzuya A, Maesako M, Asada-Utsugi M, Kubota M, Aoyagi N, Yoshioka K, Okawa K, Inoue H, et al: $\mathrm{N}$-cadherin regulates p38 MAPK signaling via association with JNK-associated leucine zipper protein: Implications for neurodegeneration in Alzheimer disease. J Biol Chem 286: 7619-7628, 2011.

9. Kashef K, Lee CM, Ha JH, Reddy EP and Dhanasekaran DN: JNK-interacting leucine zipper protein is a novel scaffolding protein in the Galpha13 signaling pathway. Biochemistry 44: 14090-14096, 2005.

10. Lee CM, Onésime D, Reddy CD, Dhanasekaran N and Reddy EP: JLP: A scaffolding protein that tethers JNK/p38MAPK signaling modules and transcription factors. Proc Natl Acad Sci USA 99: 14189-14194, 2002.

11. Nguyen Q, Lee CM, Le A and Reddy EP: JLP associates with kinesin light chain 1 through a novel leucine zipper-like domain. J Biol Chem 280: 30185-30191, 2005.

12. Takaesu G, Kang JS, Bae GU, Yi MJ, Lee CM, Reddy EP and Krauss RS: Activation of p38alpha/beta MAPK in myogenesis via binding of the scaffold protein JLP to the cell surface protein Cdo. J Cell Biol 175: 383-388, 2006.

13. Kanojia D, Garg M, Gupta S, Gupta A and Suri A: Sperm-associated antigen 9, a novel biomarker for early detection of breast cancer. Cancer Epidemiol Biomarkers Prev 18: 630-639, 2009.

14. Garg M, Kanojia D, Suri S and Suri A: Small interfering RNA-mediated down-regulation of SPAG9 inhibits cervical tumor growth. Cancer 115: 5688-5699, 2009.

15. Garg M, Kanojia D, Salhan S, Suri S, Gupta A, Lohiya NK and Suri A: Sperm-associated antigen 9 is a biomarker for early cervical carcinoma. Cancer 115: 2671-2683, 2009. 
16. Garg M, Kanojia D, Suri S, Gupta S, Gupta A and Suri A Sperm-associated antigen 9: A novel diagnostic marker for thyroid cancer. J Clin Endocrinol Metab 94: 4613-4618, 2009.

17. Kanojia D, Garg M, Gupta S, Gupta A and Suri A: Sperm-associated antigen 9 is a novel biomarker for colorectal cancer and is involved in tumor growth and tumorigenicity. Am J Pathol 178: 1009-1020, 2011.

18. Schajowicz F, Sissons HA, and Sobin LH: The World Health Organization's histologic classification of bone tumors. A commentary on the second edition. Cancer 75: 1208-1214, 1995.

19. Wang Y, Dong Q, Miao Y, Fu L, Lin X and Wang E: Clinical significance and biological roles of SPAG9 overexpression in non-small cell lung cancer. Lung Cancer 81: 266-272, 2013.

20. Schmittgen TD and Livak KJ: Analyzing real-time PCR data by the comparative C(T) method. Nat Protoc 3: 1101-1108, 2008.

21. Garg M, Kanojia D, Khosla A, Dudha N, Sati S, Chaurasiya D, Jagadish N, Seth A, Kumar R, Gupta S, et al: Sperm-associated antigen 9 is associated with tumor growth, migration and invasion in renal cell carcinoma. Cancer Res 68: 8240-8248, 2008

22. Xie C, Fu L, Liu N and Li Q: Overexpression of SPAG9 correlates with poor prognosis and tumor progression in hepatocellular carcinoma. Tumour Biol 35: 7685-7691, 2014.

23. Jagadish N, Rana R, Selvi R, Mishra D, Garg M, Yadav S, Herr JC, Okumura K, Hasegawa A, Koyama K and Suri A: Characterization of a novel human sperm-associated antigen 9 (SPAG9) having structural homology with c-Jun N-terminal kinase-interacting protein. Biochem J 389: 73-82, 2005.

24. Gantulga D, Tuvshintugs B, Endo Y, Takino T, Sato H, Murakami S and Yoshioka K: The scaffold protein c-Jun NH2-terminal kinase-associated leucine zipper protein regulates cell migration through interaction with the G protein $\mathrm{G}$ (alpha 13). J Biochem 144: 693-700, 2008

25. Kashef K, Radhakrishnan R, Lee CM, Reddy EP and Dhanasekaran DN: Neoplastic transformation induced by the gep oncogenes involves the scaffold protein JNK-interacting leucine zipper protein. Neoplasia 13: 358-364, 2011.

26. Miao ZF, Wang ZN, Zhao TT, Xu YY, Wu JH, Liu XY, Xu H, You Y and $\mathrm{Xu}$ HM: Overexpression of SPAG9 in human gastric cancer is correlated with poor prognosis. Virchows Arch 467: 525-533, 2015.

27. Li H, Peng Y, Niu H, Wu B, Zhang Y, Zhang Y, Bai X and He P: SPAG9 is overexpressed in human prostate cancer and promotes cancer cell proliferation. Tumour Biol 35: 6949-6954, 2014.
28. Mehraein-Ghomi F, Kegel SJ, Church DR, Schmidt JS, Reuter QR, Saphner EL, Basu HS and Wilding G: Targeting androgen receptor and JunD interaction for prevention of prostate cancer progression. Prostate 74: 792-803, 2014.

29. Ouafik L, Berenguer-Daize $C$ and Berthois Y: Adrenomedullin promotes cell cycle transit and up-regulates cyclin D1 protein level in human glioblastoma cells through the activation of c-Jun/JNK/AP-1 signal transduction pathway. Cell Signal 21: 597-608, 2009

30. Nakachi S, Nakazato T, Ishikawa C, Kimura R, Mann DA, Senba M, Masuzaki H and Mori N: Human T-cell leukemia virus type 1 tax transactivates the matrix metalloproteinase 7 gene via JunD/AP-1 signaling. Biochim Biophys Acta 1813: 731-741, 2011.

31. Byun HJ, Hong IK, Kim E, Jin YJ, Jeoung DI, Hahn JH, Kim YM, Park SH and Lee H: A splice variant of CD99 increases motility and MMP-9 expression of human breast cancer cells through the AKT-, ERK- and JNK-dependent AP-1 activation signaling pathways. J Biol Chem 281: 34833-34847, 2006.

32. Kim MS, Park MJ, Kim SJ, Lee CH, Yoo H, Shin SH, Song ES and Lee SH: Emodin suppresses hyaluronic acid-induced MMP-9 secretion and invasion of glioma cells. Int J Oncol 27: 839-846, 2005

33. Dong QZ, Wang Y, Tang ZP, Fu L, Li QC, Wang ED and Wang EH: Derlin-1 is overexpressed in non-small cell lung cancer and promotes cancer cell invasion via EGFR-ERK-mediated up-regulation of MMP-2 and MMP-9. Am J Pathol 182: 954-964, 2013.

34. Wang J, Shi Q, Yuan TX, Song QL, Zhang Y, Wei Q, Zhou L, Luo J, Zuo G, Tang M, et al: Matrix metalloproteinase 9 (MMP-9) in osteosarcoma: Review and meta-analysis. Clin Chim Acta 433: 225-231, 2014.

35. Kim SM, Lee H, Park YS, Lee Y and Seo SW: ERK5 regulates invasiveness of osteosarcoma by inducing MMP-9. J Orthop Res 30: 1040-1044, 2012.

36. Kook SH, Son YO, Jang YS, Lee KY, Lee SA, Kim BS, Lee HJ and Lee JC: Inhibition of c-Jun N-terminal kinase sensitizes tumor cells to flavonoid-induced apoptosis through downregulation of JunD. Toxicol Appl Pharmacol 227: 468-476, 2008. 